\title{
Fatigue Life and Corrosion Fatigue Life Prediction of Welded Joints of Structural Steel Containing Planar Defects*
}

\author{
By Takao AOKI,** Keishi NAKANO,** Hiroaki FUKUHARA, ** Akira OKADA, ,* \\ Shigeo KOBAYASHI,** Katumi KIMURA ${ }^{* * *}$ and Michio INAGAKI***
}

\begin{abstract}
Synopsis
Planar defects in the butt welded joints of a high tensile steel are measured by ultrasonic testing with a point focused angle probe, and the results are related to the fatigue life prediction in air and sewater for the joints containing those defects. The fatigue lives for the defective specimens are predicted based on a linear fracture mechanics using fatigue crack growth data of weld metal in air and those of base metal in saltwater in the literature. It is shown that a reasonably close agreement between the predicted and observed lives is obtainable for both fatigue and corrosion fatigue. It is concluded that accurate prediction of the fatigue life and corrosion fatigue life is possible, provided the defect shape is detected by a nondestructive testing with the accuracy equivalent to that in this work. The significance of accuracy of measured defect size in predicting the life is also discussed.
\end{abstract}

\section{Introduction}

Welded steel structures often contain various types of residual defects such as porosity, slag inclusion, lack of fusion, lack of penetration, undercut, and crack. They also have geometric, and metallurgical discontinuities such as weld reinforcement and heat affected zone. A considerable volume of research effort has been devoted to studies of the effect of these defects or discontinuities on service performance. ${ }^{1)}$ It has been demonstrated that two dimensional planar defects, e.g., lack of fusion, lack of penetration, and crack should be the most deleterious type of defects in brittle or fatigue fracture. Therefore, the presence of planar defects cannot be accepted for most of the welded structures such as pressure vessels at present. Although many nondestructive testing (NDT) techniques such as radiographic, ultrasonic, magnetic particle, and liquid penetrant testings are widely used to detect weld defects, there is a limit in defect detection capability with these NDT techniques and they do not give direct evaluation for the degradation in weld performance. In other words, present NDT techniques are not perfect in assuring a satisfactory quality of the welds. It is necessary, therefore, to establish a rational acceptance standard for the weld defects based on the fitness-for-purpose approach, in view of the unreliability of NDT.

In this study, the sizes of planar defects such as lack of penetration and hot crack on the butt welded joint of a high tensile steel were measured by ultrasonic testing, and the results were related to the fatigue and corrosion fatigue life predictions for the defective weldments. The purpose of this investigation is to evaluate the significance of weld defects from the standpoint of structural integrity. The effect of uncertainty in defect size measurement in predicting the fatigue life and corrosion fatigue life is considered.

\section{Material and Experimental Procedures}

To ensure the realistic testing, specimens were designed to be as large as possible within the capacity of the testing machine. Specimens were fabricated from $20 \mathrm{~mm}$ thick high tensile steel plate (JIS SM50B). Chemical compositions and mechanical properties of the plate are detailed in Table 1.

Test welds were made by jointing together two plates, each $20 \times 250 \times 500 \mathrm{~mm}$, along $500 \mathrm{~mm}$ dimensions. The weld was perpendicular to the direction of plate rolling. Butt welded joints containing surface and buried lack of penetration, and pear-shaped bead hot crack were made by the automatic gas metal arc welding process. Details are given in Fig. 1. The specimens were made in such a way that a uniform defect size was achieved throughout the series. After welding, all weldments were radiographed to check the presence of required defects. Subsequently, fatigue test specimens were cut by a saw perpendicular to the weld line. All weld reinforcements were removed by grinding and rectangular specimens of $18 \mathrm{~mm}$ thick, $50 \mathrm{~mm}$ wide and $500 \mathrm{~mm}$ long were finished.

Fatigue tests were conducted on a $500 \mathrm{kN}$ closedloop servocontrolled hydraulic testing system under uniaxial constant load amplitude, in tension-tension, using sinusoidal waveform. Corrosion fatigue tests were carried out in circulating synthetic seawater with and without cathodic protection. Gyclic loading frequencies of $10 \mathrm{~Hz}$ in air and $0.5 \mathrm{~Hz}$ in seawater were adopted, and all tests were run at room temperature.

Ultrasonic testing of defects was carried out by means of the flaw tip echo method using a point focused angle probe with a newly developed spherical transducer as shown in Fig. 2. The position and size of defects were determined precisely by the differential beam path distance method using a reference test block with $\phi 3 \mathrm{~mm}$ side drill holes. Full experimental details of the method were described elsewhere. ${ }^{2-4)}$ Ultrasonic testing conditions are shown in Table 2.

* Originally published in Tetsu-to-Hagané, 71 (1985), 1170, in Japanese; formerly presented to the 106th ISIJ Meeting, October 1983, S1490, at Akita University in Akita. English version received on March 27, 1986; accepted in the final form on September $12,1986$. (C) 1986 ISIJ

** National Research Institute for Metals, Nakameguro, Meguro-ku, Tokyo 153

*** The Japan Welding Technology Center, Hon-cho, Kawasaki-ku, Kawasaki 210. 
Table 1. Chemical composition and mechanical properties of SM 50B steel, $20 \mathrm{~mm}$ in thickness.

\begin{tabular}{l|ccccc}
\hline (a) $\begin{array}{l}\text { Chemical composi- } \\
\text { tion of steel used } \\
\text { (wt\%) }\end{array}$ & $\mathrm{C}$ & $\mathrm{Si}$ & $\mathrm{Mn}$ & $\mathrm{P}$ & $\mathrm{S}$ \\
\cline { 2 - 6 } & 0.14 & 0.34 & 1.32 & 0.018 & 0.007 \\
\hline \multirow{3}{*}{\begin{tabular}{l} 
(b) $\begin{array}{l}\text { Mechanical proper- } \\
\text { ties of steel used }\end{array}$ \\
\cline { 2 - 6 }
\end{tabular}} & $\begin{array}{c}\text { Yield } \\
\text { strength } \\
\left(\mathrm{MN} / \mathrm{m}^{2}\right)\end{array}$ & $\begin{array}{c}\text { Tensile } \\
\text { strength } \\
\left(\mathrm{MN} / \mathrm{m}^{2}\right)\end{array}$ & $\begin{array}{c}\text { Elongation } \\
(\%)\end{array}$ \\
\cline { 2 - 6 } & 355 & 500 & 30 \\
\hline
\end{tabular}

(a)

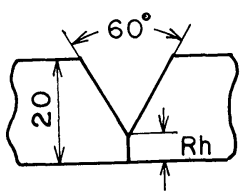

$\mathrm{Rh}=2,4,6$

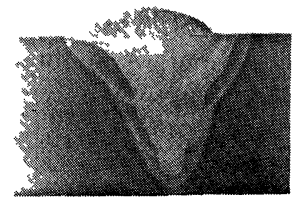

(b)

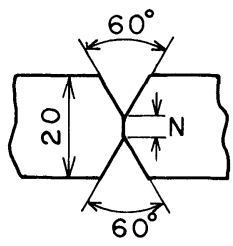

$N=8,6.3$

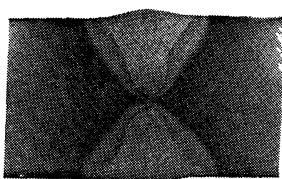

6.4

(c)

Coated electrode

arc welding

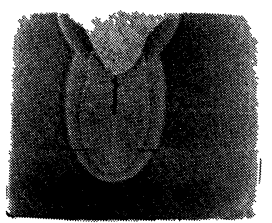

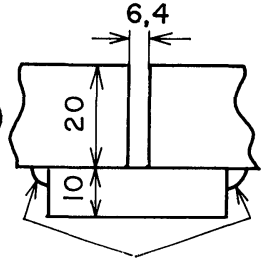

Shielding gas

Ar $25 ; 1 / \mathrm{min}+\mathrm{CO}_{2} \quad 5 ; 1 / \mathrm{min}$

In first layer

Welding current $260 \mathrm{~A}$

Welding speed $40 \mathrm{~cm} / \mathrm{min}$

Wire diameter $1.2 \mathrm{~mm}$

Over second layer

Welding current $390 \mathrm{~A}$

Welding speed $30 \mathrm{~cm} / \mathrm{min}$

Wire diameter $1.6 \mathrm{~mm}$

\section{Each layer}

Shielding gas

Ar $25: 1 / \mathrm{min}+\mathrm{CO}_{2} 5 ; 1 / \mathrm{min}$

Welding current $320 \mathrm{~A}$

Welding speed $40 \mathrm{~cm} / \mathrm{min}$

Wire diameter $1.6 \mathrm{~mm}$

\section{In first layer}

Shielding gas

$\mathrm{CO}_{2} 25 ; 1 / \mathrm{min}$

Welding current $470 \mathrm{~A}$

Welding speed $32.5 \mathrm{~cm} / \mathrm{min}$

Wire diameter $1.6 \mathrm{~mm}$

In second layer

Shielding gas

Ar $15 ; 1 / \mathrm{min}+\mathrm{CO}_{2} 15 ; 1 / \mathrm{min}$

Welding curent $365 \mathrm{~A}$

Welding speed $35 \mathrm{~cm} / \mathrm{min}$

Wire diameter $1.6 \mathrm{~mm}$

(a), (b) Surface and buried lack of penetration

(c) Hot crack

Fig. 1. Manufacturing of test welds containing various defects.

\section{Experimental Results and Analysis}

1. Improvement of Accuracy in Measuring Defect Size with Ultrasonic Testing

Figure 3 compares the estimates of the depths of
Table 2. Ultrasonic testing condition.

\begin{tabular}{l|l}
\hline Transducer & P.F.A.P.* (5Z10S50A45) \\
Flaw detector & UDF-305D \\
Couplant & Spindle oil \\
UT method & Flaw tip echo method \\
Reference block & $\phi 3$ side drill hole test block \\
\hline
\end{tabular}

* Point focused angle probe.

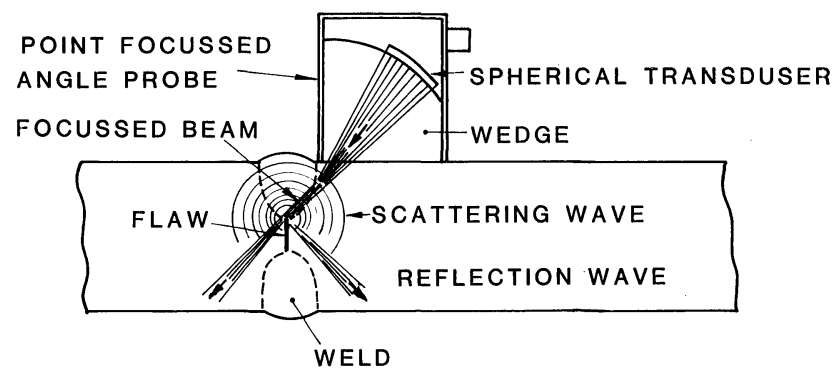

Fig. 2. Measurement of defect size by point focused angle probe.

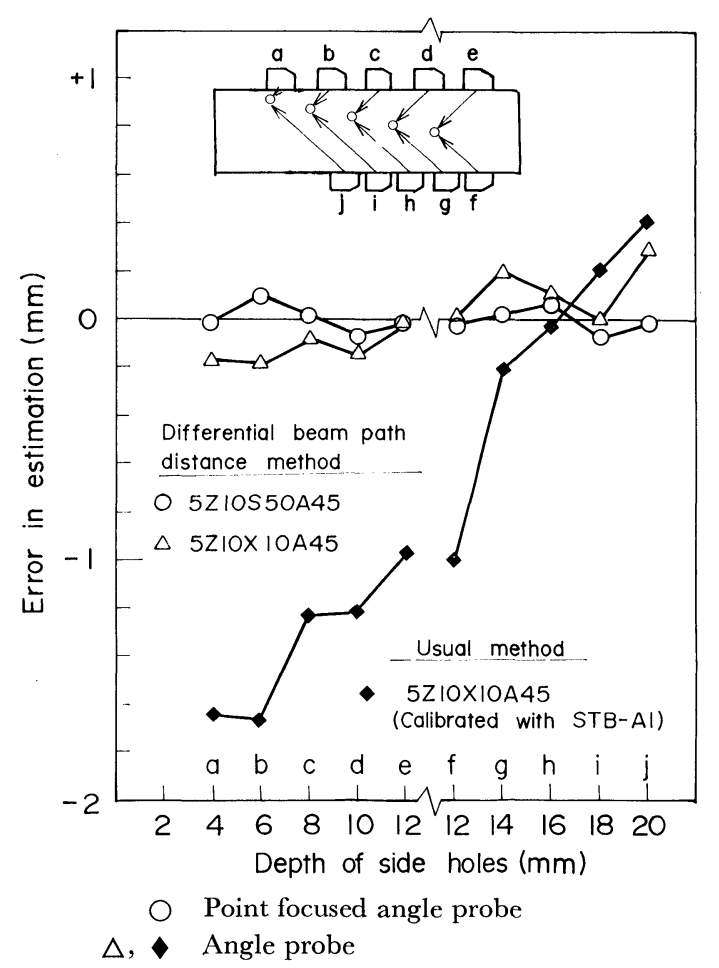

Fig. 3. Comparison of the estimated depths of side drill holes with three ultrasonic testing methods.

side drill holes of a test block by three ultrasonic angle beam methods. In the usual method ( $\bullet$, the range of measurement is adjusted by estimating the probe index and beam angle of the angle probe using a calibration block (JIS STB-Al). The method considerably underestimates the depths of shallow side holes. Furthermore, the errors in the estimate show a rapid decrease with increase in depths of side holes, and finally, an inverse tendency of overestimate is seen above the depth of about $16 \mathrm{~mm}$. On the other hand, the differential beam path distance method with a point focused angle probe $(O)$ can 
estimate the depths of side holes within $\pm 0.15 \mathrm{~mm}$ irrespective of the hole depths. Similarly, the depths of holes can be estimated with the accuracy of $\pm 0.35 \mathrm{~mm}$ by the differential beam path distance method with a usual angle probe $(\Delta)$.

In Fig. 4, an example of the measurement of weld defects with the differential beam path distance method using a point focused angle probe is shown. In the figure, the corresponding sizes measured by an optical tool microscope after fatigue fracture are compared. Owing to the irregularity of the defect tip and the contacting action of defect faces due to the weld residual stress, somewhat wider scatter in measured values is seen in comparison with the case of test block. As a result, the weld defects can be detected with the error less than $\pm 1 \mathrm{~mm}$.

\section{Measurement of Fatigue Crack Growth Rate in Air}

Growth rate of fatigue crack in the direction of thickness (L-S orientation) of plate for the base and weld metals was measured by a beach marking technique as shown in Figs. 5 and 6 . The fatigue cracks were initiated from a sharp surface slit of $0.2 \mathrm{~mm}$ wide and $3 \mathrm{~mm}$ deep of base metal and from a surface lack of penetration of $3 \mathrm{~mm}$ deep of weld metal. As can be seen in these figures, the fatigue crack growth rates, $d a / d \mathcal{N}(\mathrm{m} /$ cycle $)$, are related to the stress intensity range, $\Delta K\left(\mathrm{MN} \cdot \mathrm{M}^{-3 / 2}\right)$, by,

$$
\begin{aligned}
& d a / d \mathcal{N}=4.81 \times 10^{-13}(\Delta K)^{3.6}, \text { and } \\
& d a / d \mathcal{N}=5.41 \times 10^{-12}(\Delta K)^{2.7}, \ldots \ldots
\end{aligned}
$$

for the base metal and the weld metal, respectively.

In Fig. 7, fatigue lives of the welded joints containing various defects are demonstrated as a function on initial stress intensity ranges, $\Delta K_{0}$. Here, the values of $\Delta K_{0}$ are calculated assuming that each defect is a crack because the gap of lack of penetration is effectively in contact and the notch root radius

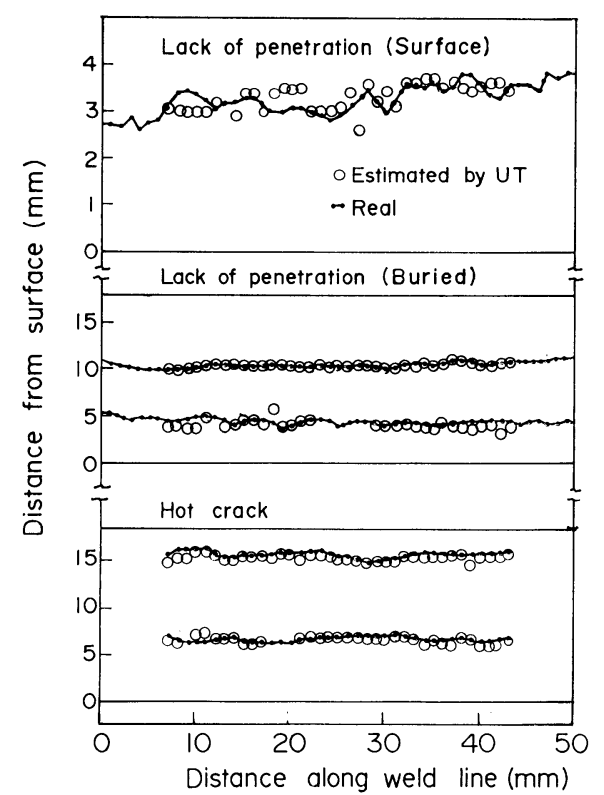

Fig. 4. Measured results of sizes of hot crack and lack of penetration. of hot crack is thought to be less than $0.1 \mathrm{~mm}$, though it shows irregular roughness as shown in Fig. 1. The values of stress intensity range corresponding to the number of cycles of $10^{7}, \Delta K\left(10^{7}\right)$, are about $5 \sim 6 \mathrm{MN} \cdot \mathrm{m}^{-3 / 2}$ much the same no matter what the

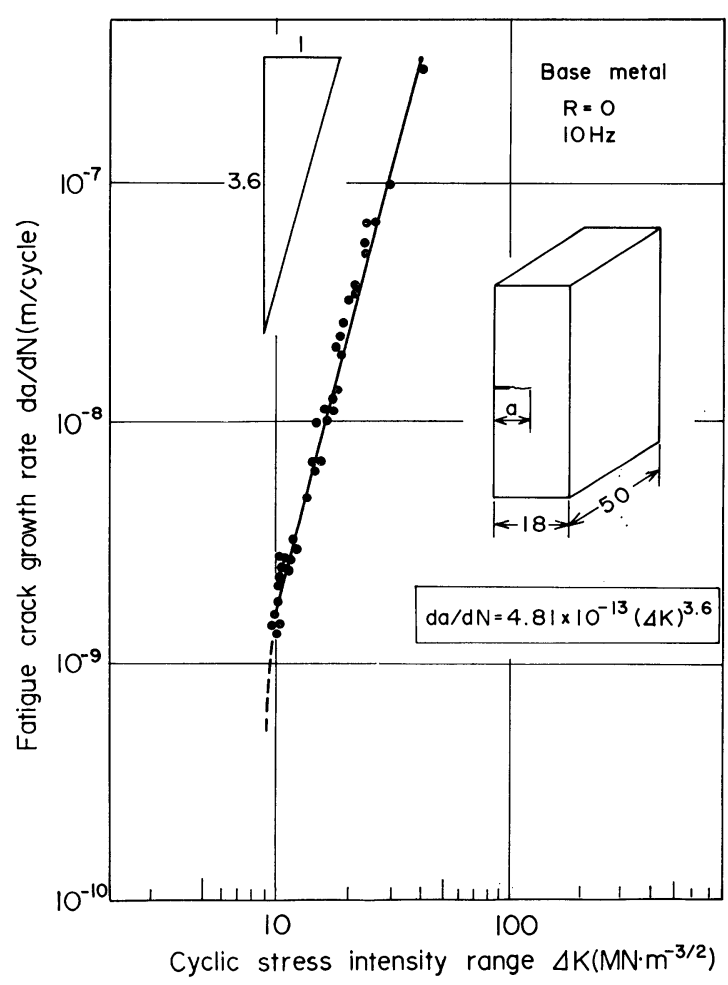

Fig. 5. Fatigue crack growth rates in air as a function of $\Delta K$ for base metal.

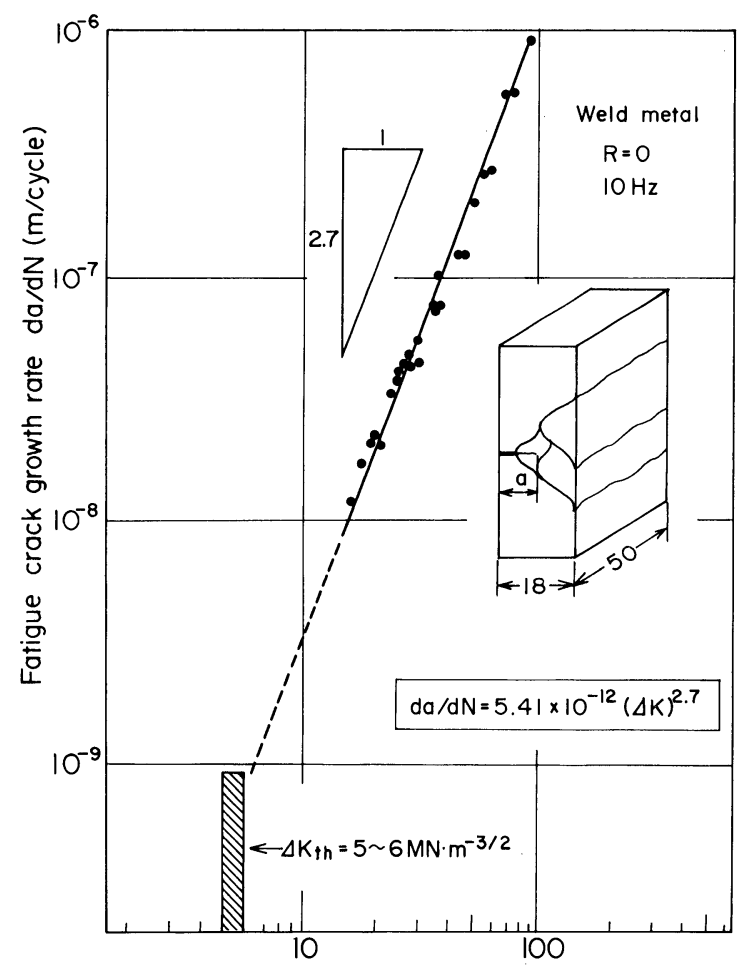

Cyclic stress intensity range $\Delta \mathrm{K}\left(\mathrm{MN} \cdot \mathrm{m}^{-3 / 2}\right)$

Fig. 6. Fatigue crack growth rates in air as a function of $\Delta K$ for weld metal. 


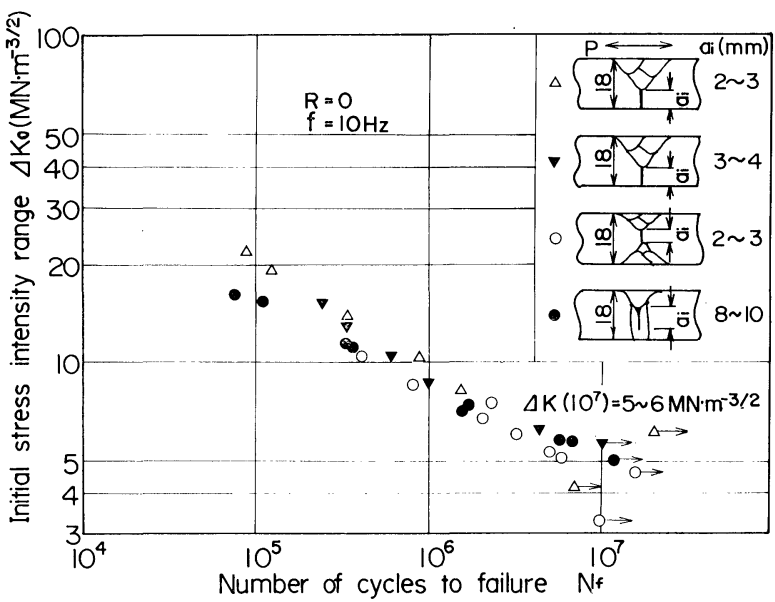

Fig. 7. Fatigue lives in air as a function of $\Delta K_{0}$ for welded joints containing various defects.

types and sizes of the defects are.

\section{Analysis of Fatigue Life in Air}

When the cyclic stress range, $\Delta \sigma$, is constant, the fatigue lives of weldments $\left(\mathcal{N}_{f}\right)$ containing sufficiently long planar defects are simply calculated by integration of Eq. (1) or (2), considering the crack growth in thickness direction alone.

$$
\mathcal{N}_{f}=\frac{1}{C(\sqrt{\pi} \cdot \Delta \sigma)^{m}} \int_{a_{i}}^{a_{f}}[\sqrt{a} \cdot f(a / W)]^{-m} d a
$$

Here, $a_{i}, a_{f}$ : the initial defect size and a final crack size at $\mathcal{N}_{f}$ calculated by assuming the fatigue fracture toughness of $K_{\mathrm{I} f}=$ $200 \mathrm{MN} \cdot \mathrm{m}^{-3 / 2}$, respectively

$f(a / w):$ a function of the ratio of crack depth $a$ to plate thickness $W$ defined as follows. ${ }^{5)}$

For surface lack of penetration,

$$
\begin{aligned}
f(a / W)= & 1.12-0.23(a / W)+10.55(a / W)^{2} \\
& -21.72(a / W)^{3}+30.39(a / W)^{4}
\end{aligned}
$$

and for buried lack of penetration or hot crack where defect sizes are expressed as $2 a$,

$$
\begin{aligned}
f(a / W)= & {\left[1-0.025(2 a / W)^{2}+0.06(2 a / W)^{4}\right] } \\
& \times \sqrt{\sec [\pi(2 a / W) / 2]} .
\end{aligned}
$$

Furthermore, the cyclic threshold stress range (fatigue limit) $\Delta \sigma_{t h}$, is given by,

$$
\Delta \sigma_{t h}=\Delta K_{t h} / \sqrt{\pi a_{i}} \cdot f(a / W)
$$

By combining Eqs. (3) and (4), a $S-\mathcal{N}$ diagram for defective weldment is obtained.

Figures 8 and 9 compare the experimentally determined total fatigue lives of defective weldments with the predicted fatigue life lines obtained from the crack growth data. Here, the values $C=5.41 \times 10^{-12}$ and $m=2.7$ obtained in weld metal were used for the prediction of $\mathcal{N}_{f}$, and fatigue limits were predicted with a value of $\Delta K_{t h}=5 \mathrm{MN} \cdot \mathrm{m}^{-3 / 2}$. As can be seen,

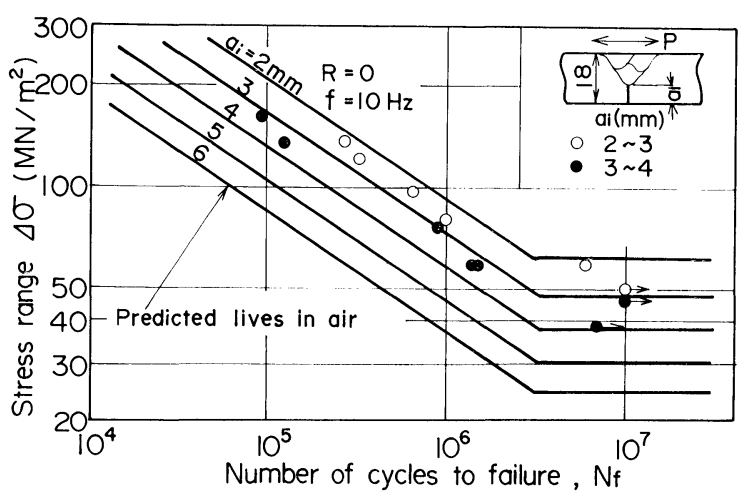

Fig. 8. Predicted and observed fatigue lives in air of specimens containing surface lack of penetration.

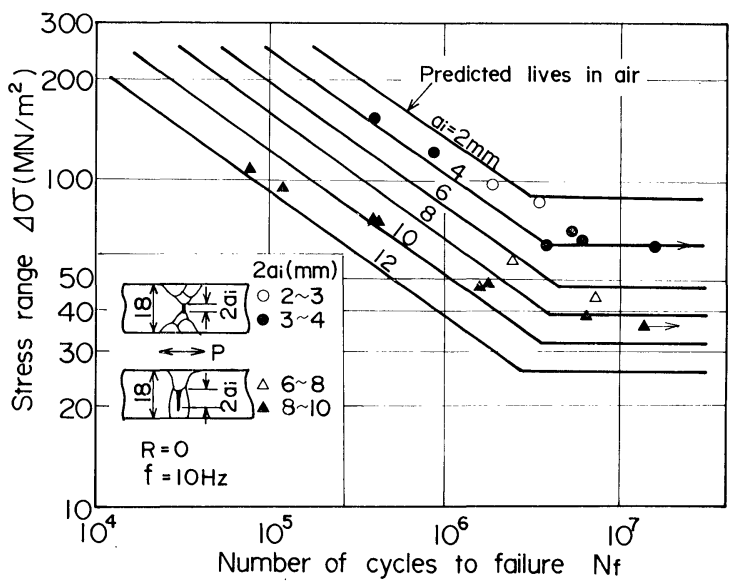

Fig. 9. Predicted and observed fatigue lives in air of specimens containing buried lack of penetration and hot crack.

reasonably close agreement between the predicted and observed values was obtained for both the surface and buried lack of penetration. Some disagreement was noticed for the case of hot crack where the crack showed comparatively irregular roughness. It may be concluded that the fatigue life can be predicted with a sufficient accuracy for engineering usage if the position and size of defects are detected by NDT within $\pm 1 \mathrm{~mm}$ as in the present work.

\section{Analysis of Corrosion Fatigue Life in Synthetic Seawater}

Analysis of corrosion fatigue life is more difficult than that in air because its growth rate is more sensitive to various factors such as environmental condition, stress ratio, cyclic frequency. Although a lot of data on the corrosion fatigue crack growth in seawater type solutions are now available, considerable scatter in data is seen depending on the researchers and their experimental techniques used. Particularly, few reliable data at low-stress and longlife regions are yet available. Furthermore, taking the wide spread use of cathodic protection for offshore structures into account, it is also important to grasp more detailed role of cathodic protection in the corrosion fatigue life predictions.

The available corrosion fatigue growth data ${ }^{6-8)}$ indicate that the crack growth behavior may be 
characterized by two regions in the case of free corrosion potential and by three regions in the case of cathodic protection potential. Vosikovsky ${ }^{9}$ has shown, from the corrosion fatigue study of X-65 steel in $3.5 \% \mathrm{NaCl}$ solution, a distinct functional dependence of crack growth rates on $\Delta K$, frequency, and cathodic potential. The crack growth behavior in corrosion fatigue under the conditions of $0.5 \mathrm{~Hz}$ and $R=0$ used in this work was examined following the instructions of Vosikovsky and the results are shown in Fig. 10. Here, a correction for load ratio $R$ was made using a correlation equation, ${ }^{10)} d a / d \mathcal{N}=C(\Delta K+$ $4 R)^{m}$, since all the data of Vosikovsky were obtained at $R=0.2$. Subsequently, the acceleration ratio of growth rate in saltwater to that in air at each $\Delta K$ was obtained. There are some experimental evidences ${ }^{10,11)}$ showing that the crack growth rates in corrosion fatigue of low strength steels in saltwater are accelerated by analogous ratios at respective $\Delta K$ with the changes in reference data in air for free corrosion and cathodic protection. Therefore, the crack growth rates in corrosion fatigue of the weld metal of SM50B steel were calculated tentatively by multiplying the growth rates in air by the above acceleration ratios at corresponding $\Delta K$.

Based on the corrosion fatigue crack growth behavior shown in Fig. 10, corrosion fatigue lives of welded joints containing surface lack of penetration were estimated in the same manner as was done in air. The corrosion fatigue lives at free corrosion potential can be obtained by the sum of life $\mathcal{N}_{\mathrm{I}}$ at region I and $\mathcal{N}_{11}$ at region II as,

$$
\begin{aligned}
& \mathcal{N}_{f} \text { (free corrosion) }=\mathcal{N}_{\mathrm{I}}+\mathcal{N}_{\mathrm{II}} \\
& =\frac{1}{C_{\mathrm{I}}(\sqrt{\pi} \cdot \Delta \sigma)^{m_{\mathrm{I}}}} \int_{a_{i}}^{a_{c}}[\sqrt{a} \cdot f(a / W)]^{-m_{\mathrm{I}}} d a \\
& \quad+\frac{1}{C_{\mathrm{II}}(\sqrt{\pi} \cdot \Delta \sigma)^{m_{\mathrm{II}}}} \int_{a_{c}}^{a_{f}}[\sqrt{a} \cdot f(a / W)]^{-m_{1 \mathrm{II}}} d a
\end{aligned}
$$

where, $G_{\mathrm{I}}=6.3 \times 10^{-13}, \quad m=3.9, G_{\mathrm{II}}=4.4 \times 10^{-10}, \quad m=$ 1.9 as given in Fig. 10, $a_{c}$ is a crack size at the transition point from region $\mathrm{I}$ to region $\mathrm{II}$, and $a_{i}$, $a_{f}, f(a / W)$ have the same meaning as in Eq. (3). Similarly, corrosion fatigue lives at cathodic protection potential are estimated by the sum of lives of three regions.

$$
\begin{aligned}
& \mathcal{N}_{f} \text { (cathodic protection) } \\
&= \mathcal{N}_{\mathrm{I}}+\mathcal{N}_{\mathrm{II}}+\mathcal{N}_{\mathrm{III}} \\
&= \frac{1}{C_{\mathrm{I}}^{\prime}(\sqrt{\pi} \cdot \Delta \sigma)^{m_{\mathrm{I}}^{\prime}}} \int_{a_{i}}^{a_{c}^{\prime}}[\sqrt{a} \cdot f(a / W)]^{-m_{\mathrm{I}}^{\prime}} d a \\
&+\frac{a_{c}^{\prime \prime}-a_{c}^{\prime}}{C_{\mathrm{II}}^{\prime}}+\frac{1}{C_{\mathrm{III}}^{\prime}(\sqrt{\pi} \cdot \Delta \sigma)^{m_{\mathrm{III}}^{\prime}}} \\
& \times \int_{a_{c}^{\prime \prime}}^{a_{f}}[\sqrt{a} \cdot f(a / W)]^{-m_{\mathrm{III}}^{\prime}} d a \ldots \ldots \ldots \ldots \ldots . . . . . .
\end{aligned}
$$

where $, \quad C_{\mathrm{I}}^{\prime}=3.2 \times 10^{-15}, \quad m_{1}^{\prime}=6.3, \quad C_{\mathrm{II}}^{\prime}=2.26 \times 10^{-7}$, $C_{1 \mathrm{II}}^{\prime}=6.5 \times 10^{-12}$, and $m_{1 \mathrm{II}}^{\prime}=2.7$, and $a_{c}^{\prime}$, $a_{c}^{\prime \prime}$ are crack sizes at the transition points from region $I$ to region II and from region II to region III, respectively.

Figures 11 and 12 show a comparison of experi- mentally determined total corrosion fatigue lives of welded joints containing surface lack of penetration with the predicted life curves obtained from Eqs. (5) and (6) neglecting the difference in alloy composition and environmental variables. At free corrosion potential, as can be seen in Fig. $11, \mathcal{N}_{\mathrm{I}}$ and $\mathcal{N}_{\text {II }}$ take part in

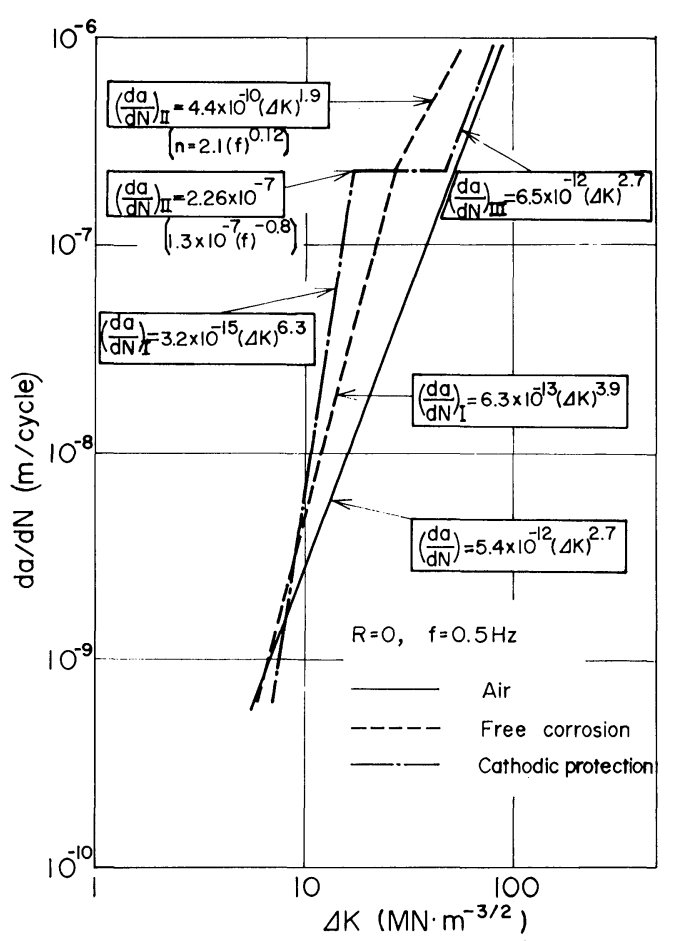

Fig. 10. Schematic illustration of corrosion fatigue crack growth rates in saltwater based on the data of Vosikovsky. ${ }^{9)}$

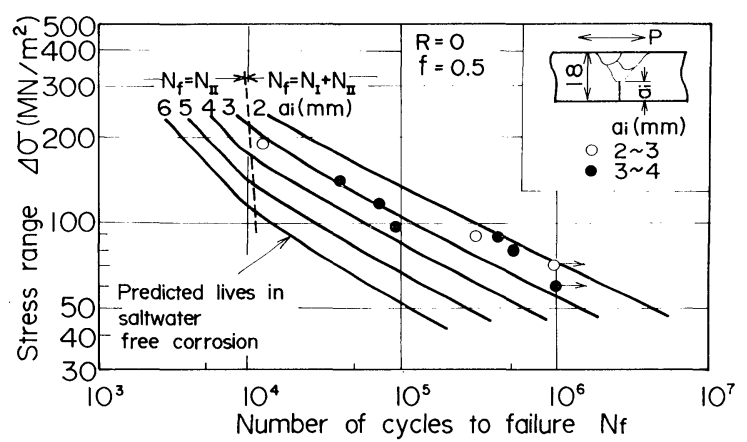

Fig. 11. Predicted and observed corrosion fatigue lives at free corrosion potential.

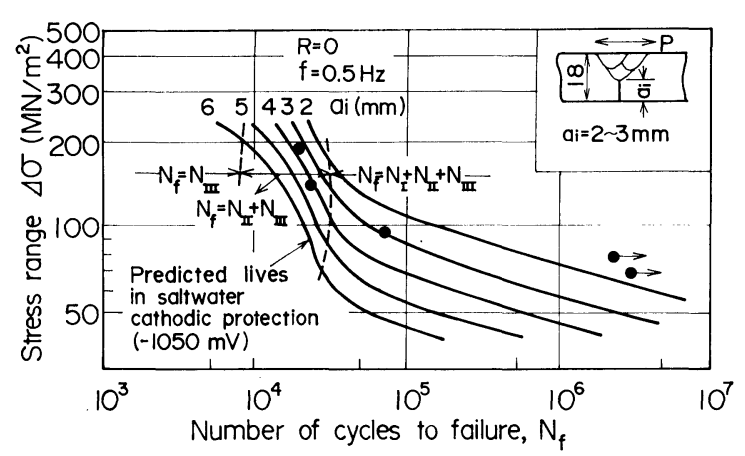

Fig. 12. Predicted and observed corrosion fatigue lives at a cathodic protection potential of $-1050 \mathrm{mV}$ (SCE). 
the total lives above the cycles to failure of about $10^{4}$, but only $\mathcal{N}_{\text {II }}$ does below that cycles resulting in a knee in the life curves. Although the effect of defect size is not so clear as the case in air on account of limited data, the experimental lives are found to fall practically within the predicted life lines of 2 $4 \mathrm{~mm}$.

At cathodic potential, as shown in Fig. 12, $\mathcal{N}_{\text {II }}$ and $\mathcal{N}_{\text {III }}$ take part in the total lives at the range of cycles from $9 \times 10^{3}$ to $3 \times 10^{4}$ and the crack growth process in the plateau (region II of chin line in Fig. 10) takes the major portion of the total life. Hence, the effect of crack size on total life is decreased relatively at intermediate stress ranges. Although the experimental lives at the stress ranges above $100 \mathrm{MN} \cdot \mathrm{m}^{-3 / 2}$ are slightly shorter than the predicted lines, the life prediction at cathodic protection potential is also possible as well as the case of free corrosion potential. At low stress ranges, however, the experimental lives tend to shift to higher cycles than predicted lines. This may be originated from the fact that the life predictions were made based on the data obtained in $3.5 \% \mathrm{NaCl}$ solution. It is well known that when a cathodic potential is applied to steel in seawater, the $\mathrm{PH}$ at the metal surface can rise to levels near 11, leading to the precipitation of calcium and magnesium compounds as a calcareous coating. ${ }^{12}$ ) This calcareous scale (which do not form from $\mathrm{NaCl}$ solution) is also deposited within the growing corrosion fatigue cracks in sufficient quantities to wedge open the cracks as the tensile stress is relaxed in every stress cycle. Thus, the crack growth rates are retarded still more at low stress ranges because the effective stress intensity range is reduced more effectively in these ranges.

\section{Discussion}

\section{Accuracy of Measured Defect Size and Fatigue Life Prediction}

Fatigue life, $\mathcal{N}_{f}$, of the welded joints containing defects is usually estimated taking various factors into account: initial defect size, material constant $\left(K_{\text {Ie }}\right.$, $C, m)$ stress range, errors in fabrication (angular distortion and misfit) and so on. However, these factors themselves involve considerable uncertainty by nature. In case that the degree of uncertainty in predicting $\mathcal{N}_{f}$ is estimated after considering the uncertainty of each factor, it has been shown that the defect size affects the most as a whole. ${ }^{13)}$ This implies that the reliability of NDT should be the most important factor for assessing the acceptance level of weld defects.

Putting together the questionnaire survey carried out recently by the Japan Pressure Vessel Research Council (JPVRG), ${ }^{14}$ the report of open inspection for the spherical gas holders made by high tension steels in Kanagawa Prefecture, ${ }^{15)}$ and the experimental study, ${ }^{16)}$ the minimum defect size which can be detected practically, without any omission, with the present NDT techniques is thought to be about $10 \mathrm{~mm}$ long by $5 \mathrm{~mm}$ deep. On the other hand, most defects found in the actual weldments were smaller than that minimum size, ${ }^{14,15)}$ and consequently, not only the accuracy but also the probability for detecting the weld defects are now becoming a matter of great concern.

Figure 13 shows the effect of error in measuring the defect size on the estimates of $\Delta \sigma_{t h}$ and $\mathcal{N}_{f}$ in air at $\Delta \sigma=100 \mathrm{MN} / \mathrm{m}^{2}$ for the specimen containing surface lack of penetration of $4 \mathrm{~mm}$ in depth. For example, when the defect size is estimated with an error of $-1.6 \mathrm{~mm}$ by the usual method as shown in Fig. 3, $\mathcal{N}_{f}$ and $\Delta \sigma_{t h}$ are overestimated by factors of 3 and 1.4, respectively. This results in a nonconservative evaluation from the standpoint of fracture control for safety.

The effect of accuracy in measuring defect size on the uncertainty in prediction $\mathcal{N}_{f}$ or $\Delta \sigma_{t h}$ can be compared quantitatively by obtaining the values of sensitivity index, $\alpha_{i}$ as follows. ${ }^{17)}$

For $\mathcal{N}_{f}$,

$$
\alpha_{i}=\left(\frac{\partial \mathcal{N}_{f}}{\partial X_{i}}\right)_{X_{i}=\bar{X}_{i}} \cdot\left(\frac{\bar{X}_{i}}{\overline{\mathcal{N}}_{f}}\right)
$$

where, $X_{i}$, which has an effect upon $\mathcal{N}_{f}$, is a parameter with uncertainty, and $\bar{X}_{i}$ and $\overline{\mathcal{N}}_{f}$ are their expected values. The partial derivative in Eq. (7) can be approximated as,

$$
\begin{aligned}
\left(\frac{\partial \mathcal{N}_{f}}{\partial X_{i}}\right)_{X_{i}=\bar{X}_{i}}= & \left\{\mathcal { N } _ { f } \left(\bar{X}_{1}, \bar{X}_{2} \ldots \bar{X}_{i}\right.\right. \\
& \left.+\Delta X_{i} \ldots \bar{X}_{n}\right)-\mathcal{N}_{f}\left(\bar{X}_{1}, \bar{X}_{2} \ldots \bar{X}_{i}\right. \\
& \left.\left.-\Delta X_{i} \ldots \bar{X}_{n}\right)\right\} / 2 \Delta X_{i} \ldots \ldots \ldots \ldots \ldots \ldots \ldots \ldots \ldots
\end{aligned}
$$

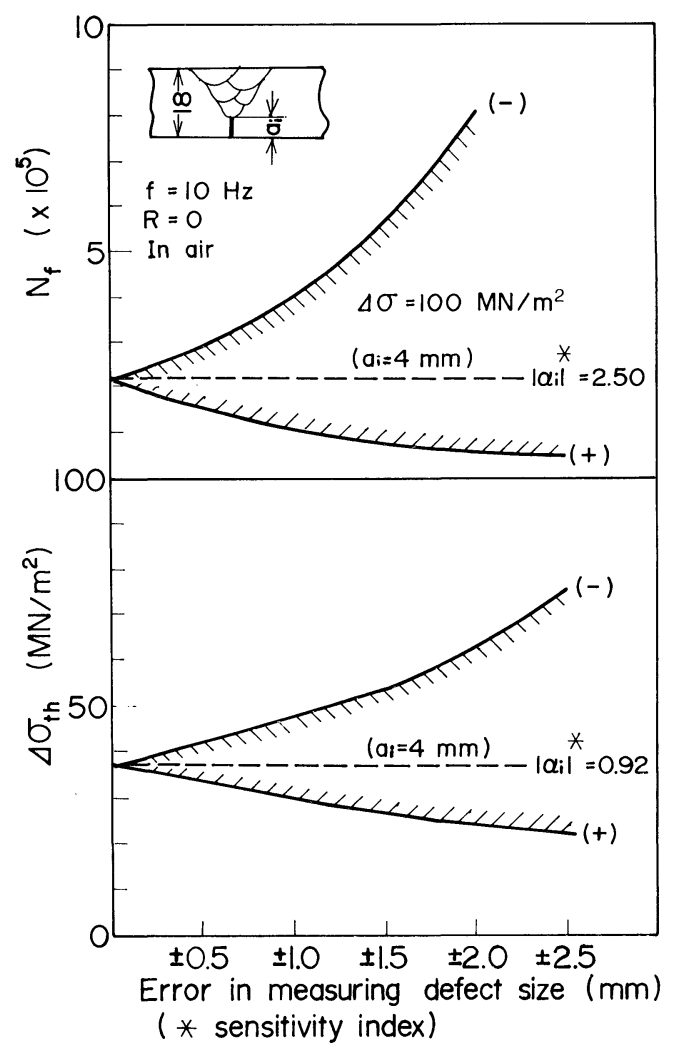

Fig. 13. Effect of error in measuring defect size on the estimation of threshold stress range $\Delta \sigma_{t h}$ and fatigue life $\mathcal{N}_{f}$ for specimens containing surface lack of penetration. 
As an example, we now consider the simple case that the $\mathcal{N}_{f}$ in air is obtained by Eq. (3). Substituting the parameters $\bar{X}_{1} \sim \bar{X}_{n}$ by $\Delta \sigma=100 \mathrm{MN} / \mathrm{m}^{2}, a_{i}=4 \mathrm{~mm}$, $a_{f}=15 \mathrm{~mm}, C=5.41 \times 10^{-12}, m=2.7$, and $W=18 \mathrm{~mm}$, and putting $\Delta a_{i}=0.1 \mathrm{~mm}$, the value $\left|\alpha_{i}\right|$ of the defect size for $\mathcal{N}_{f}$ is calculated to be 2.5. Similarly, with $\Delta \sigma_{t h}$ in Eq. (4), substituting $\bar{X}_{1} \sim \bar{X}_{n}$ by $\Delta K_{t h}=5 \mathrm{MN}$. $\mathrm{m}^{-3 / 2}, \quad a_{i}=4 \mathrm{~mm}, \quad W=18 \mathrm{~mm}$, and putting $\Delta a_{i}=$ $0.1 \mathrm{~mm}$, the value $\left|\alpha_{i}\right|$ of 0.92 is obtained. These values are also shown in Fig. 13.

These values of $\left|\alpha_{i}\right|$ depend on the expected values of parameters such as defect size, stress range and the like. In Fig. 14, the dependence of $\left|\alpha_{i}\right|$ of defect size for $\mathcal{N}_{f}$ on the stress range $\Delta \sigma$ is shown under three environmental conditions of air, free corrosion, and cathodic protection. It is seen that whereas $\left|\alpha_{i}\right|$ is independent of $\Delta \sigma$ and constant in air, marked decrease in $\left|\alpha_{i}\right|$ with $\Delta \sigma$ is apparent under the conditions of free corrosion and of cathodic protection in particular. This behavior results from the change of $m$ values and the occurrence of plateau region in the $d a / d \mathcal{N}-\Delta K$ curves in Fig. 10. This shows that the significance of accuracy in measuring defect size for the fatigue life prediction is different with each environment used.

\section{On the Effect of Weld Residual Stress}

Residual stress due to welding is a result of the different heating and cooling rates at various locations in the material. In analyzing the fatigue crack growth behavior of weldments, residual stress distribution must be considered..$^{18,19)}$ However, because of the inevitable redistribution of residual stress in the process of preparing specimens from the whole weldments, the residual stress pattern in the specimens is probably different from that in weldments. Thus, it should be noted that a direct correspondence is not always obtained between the crack growth behavior in the specimens and its overall position in the weldments. In this work, the fatigue life was predicted using the crack growth data in weld metal of the specimen with surface lack of penetration in which residual stress effect was contained. Strictly speaking, the residual stress pattern in the specimens with buried lack of penetration or hot crack may be different from that of surface lack of penetration. Therefore,

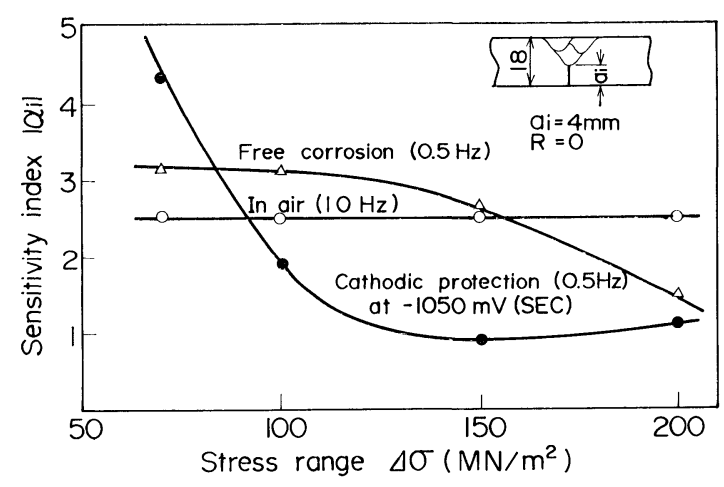

Fig. 14. Sensitivity indexes of defect size for fatigue life as a function of stress range. the fatigue life predictions of the former are expected to be more or less influenced. However, even with the crack growth data of base metal, accurate fatigue life predictions for engineering usage could be obtained as well as the case of weld metal in the range studied. It is concluded that the effect of residual stress on the fatigue life predictions is relatively small in this work.

\section{Conclusions}

The results of the present investigation may be summarized as follows.

(1) In the examination of the weld defects with ultrasonic testing, the size and position of planar defects such as lack of penetration and hot crack can be detected within $\pm 1 \mathrm{~mm}$ by using the differential beam path method with a point focused angle probe.

(2) The stress intensity range, $\Delta K\left(10^{7}\right)$, in air of the welded joints containing various planar defects remained in the same range of about $5 \sim 6 \mathrm{MN} \cdot \mathrm{m}^{-3 / 2}$ irrespective of the types and sizes of the defects.

(3) It is verified experimentally that the fatigue lives in air of the welded joints containing planar defects can be predicted with a sufficient accuracy for engineering usage if the defect sizes are determined with the accuracy of $\pm 1 \mathrm{~mm}$ as in the present work.

(4) The corrosion fatigue lives of the welded joints containing surface planar defects can be predicted by the same manner as in air, assuming two fatigue crack growth equations for free corrosion and three equations for cathodic protection respectively.

(5) The influence of the accuracy in measuring defect size on the fatigue life predictions was greater than that of fatigue limit. The sensitivity indexes of defect size for fatigue life were independent of $\Delta \sigma$ in air, but marked dependence on $\Delta \sigma$ was apparent under the conditions of free corrosion and of cathodic protection in particular.

\section{REFERENGES}

1) C. D. Lundin: WRG Bull., 222 (1976), 1.

2) NDI Subcommittee 202: J. Japan Soc. Nondestruct. Inspec., 30 (1981), 30.

3) K. Kimura: JSNDI Technical Committee 2 Report, No. 2644, (1977), 1.

4) S. Matsumoto, K. Kimura and H. Fukuhara: JSNDI Technical Committee 2 Report, No. 2669, (1978), 23.

5) H. Okamura: An Introduction to Linear Fracture Mechanics, Baifu-kan, Tokyo, (1976), 217.

6) C. E. Jaske, J. H. Payer and V. S. Balint: Corrosion Fatigue of Metals in Marine Environments, Battelle Press, Ohio, (1981), 35.

7) B. Tomkins: Metal Sci., 13 (1979), 387.

8) P. W. Lohne: Metal Construction, 11 (1979), 382.

9) O. Vosikovski: J. Eng. Mat. and Tech., 98 (1975), 298.

10) O. Vosikovski: J. Testing and Evaluation, 8 (1980), 68.

11) O. Vosikovski: Welding J., 59 (1980), Research Suppl., 225-s.

12) J. L. Nickols: Material Performance, 2 (1963), 46.

13) M. Urioka, M. Okumura, E. Kamisaka and T. Itoh: Proc. Colloquium on Practical Application of Fracture Mechanics, ILW, Abington, U.K., (1979), 246.

14) M. Inagaki: Preprint 1st Symposium on Reliability of Pressure Vessels, JPVRG, ISIJ, Tokyo, (1984), 52. 
15) M. Kawahara: Preprint 8th Symposium on Material Defect and Its Evaluation, Kanto Branch of Japan Soc. Mat. Sci., Tokyo, (1984), 1.

16) P. E. Packman, H. S. Pearson, J. S. Owens and G. Young: J. Mater., 4 (1969), 666.

17) H. Okamura and H. Itagaki: Statistical Treatment of Strength, Baifu-kan, Tokyo, (1979), 243.
18) A. Ota, E. Sasaki, M. Kamakura, M. Nihei, M. Kosuge, M. Kanao and M. Inagaki: J. Japan Weld. Soc., 50 (1978), 161.

19) B. M. Kapadia: Fatigue Testing of Weldments, ASTM Spec. Tech. Publ. No. 648, ed. by D. W. Hoeppner, (1978), 244. 